\title{
Neighborhood Environment Is Associated with Overweight and Obesity, Particularly in Older Residents: Results from Cross-Sectional Study in Dutch Municipality
}

Polina Putrik, Ludovic van Amelsvoort, Nanne K. De Vries, Suhreta Mujakovic, Anton E. Kunst, Hans van Oers, Maria Jansen, and IJmert Kant

\begin{abstract}
We explored whether overweight and obesity were associated with the physical and social environment at neighborhood level. Data from Maastricht municipality survey (the Netherlands) were used ( $n=9771$ adults). Multinomial regression models were computed (outcome being normal weight, overweight, or obese). We found inconsistent associations between neighborhood social and physical environment characteristics and overweight and obesity in the total sample. The effects were more consistent and stronger for older residents (>65) and obesity as an outcome. Better scores on traffic nuisance, green space, social cohesion, nuisance, and safety were associated with lower odds of obesity among elderly (OR ranged between 0.71 [95\% CI 0.44 to 0.93] to 0.85 [95\% CI 0.74 to 0.96] for each point of improvement in neighborhood social and physical environment (scale 0-10)). We showed that there are neighborhood-level factors that are associated with obesity, particularly in elderly residents. These could be targeted in preventive strategies outside health care settings.
\end{abstract}

KEYWORDS Neighborhood, Social and physical environment, Obesity, Overweight, Socioeconomic inequalities

\section{INTRODUCTION}

The worldwide prevalence of obesity has nearly doubled since 1980 according to the World Health Organization. ${ }^{1}$ In the Netherlands, the prevalence of overweight and obesity increased from $33 \%$ in 1981 to $48 \%$ in 2012 and the prevalence of obese persons rose from 5 to $12 \% .^{2}$ It is well established that an increase in obesity rates

Putrik and Vries are with the Department of Health Promotion, School for Public Health and Primary Care (CAPHRI), Maastricht University, Maastricht, The Netherlands; Putrik, Mujakovic, and Jansen are with the Academic Collaborative Centre for Public Health Limburg, Public Health Service Southern Limburg, Geleen, Netherlands; Amelsvoort and Kant are with the Department of Epidemiology, School for Public Health and Primary Care (CAPHRI) Maastricht University, Maastricht, The Netherlands; Kunst is with the Department of Public Health, Academic Medical Center, Amsterdam, The Netherlands; Oers is with the National Institute of Public Health and the Environment (RIVM), Bilthoven, The Netherlands; Oers is with the Tranzo Scientific Centre for Care and Welfare, Tilburg University, Tilburg, The Netherlands; Jansen is with the Department of Health Services Research, School for Public Health and Primary Care (CAPHRI), Maastricht University, Maastricht, The Netherlands.

Correspondence: Polina Putrik, Academic Collaborative Centre for Public Health Limburg, Public Health Service Southern Limburg, Geleen, Netherlands. (E-mail: polina.putrik@maastrichtuniversity.nl)

Electronic supplementary material The online version of this article (doi:10.1007/s11524-015-9991-y) contains supplementary material, which is available to authorized users. 
leads to a rapid growth of health care costs associated with diabetes, cardiovascular diseases, musculoskeletal conditions, and some forms of cancer. ${ }^{1}$ It has been suggested that four main factors relate to obesity: built environment, social environment, individual behavior, and individual genetic factors. ${ }^{3}$ In this context, experts talk about obesogenic environments, i.e., environments that promote individual obesity-enhancing behaviors and thus obesity., ${ }^{3,4}$ For example, the immediate environment can increase or reduce opportunities for healthy eating as well as stimulate or discourage physical activity (PA). The effect of the abovementioned factors are suggested to be especially pronounced in those persons who are genetically predisposed to obesity. ${ }^{3}$

While many interventions have been developed to address obesity at an individual level (e.g., interventions targeting individual behavior related to nutrition and physical activity, but also antiobesity drugs or surgery ${ }^{5-8}$ ), these are not able to control the emerging obesity pandemic. ${ }^{9,10}$ In a view of this growing consensus, it has been suggested that approaches that target community (as opposed to individual) risk factors could add to traditional individual-based obesity interventions. ${ }^{11}$ Neighborhood socioeconomic deprivation has previously been shown to be associated with obesity in developed countries, including the Netherlands. ${ }^{5,12-16} \mathrm{~A}$ more specific focus on neighborhood determinants of obesity may offer more "upstream" (population level) preventive strategies and reach larger population groups. ${ }^{11}$ In view of this, there is an increasing interest in the potential of population-level interventions to prevent overweight and obesity. Such interventions would require intervening in the social and physical environment in which individuals live.

To our knowledge, only a few studies have explored a broad range of neighborhood characteristics and their relative importance for overweight and/or obesity, while other studies have focused on one or a few particular aspects of neighborhood in relation to excessive weight. The majority of such evidence has come from the USA, and study findings have been inconclusive. While some studies found that the built environment, green space, neighborhood density, walkability, distance to parks, traffic, and cleanliness of the neighborhood tended to be associated with overweight and/or obesity ${ }^{4,5,11-17}$, others found no proof for many of these associations. ${ }^{18,19}$ Among studies performed in the Netherlands, only one focused on specific aspects of the neighborhood environment in relation to obesity as an outcome; it found that less crime was positively associated with use of active transportation and more cycling, in turn, was associated with lower BMI among elderly male residents. ${ }^{20}$ The relationship between neighborhood characteristics and physical activity as an outcome has been more frequently explored, but findings remain inconsistent. ${ }^{21-26}$ So far, therefore, the available evidence about links between the neighborhood environment and obesity appears to be largely indirect and inconclusive. Gender has been pointed out as a potential effect moderator by several studies, but evidence regarding the moderating effect of other demographic or socioeconomic factors is limited, and further examination of potential moderators is warranted. ${ }^{11,25,27}$ While problems of potential selection mechanisms (in addition to or instead of causal relationships) in the interpretation of associations between neighborhood environment and health are difficult to overcome, ${ }^{28}$ investigating these relationships for different age groups could be particularly informative, as selection may be more likely to occur among younger persons who are more mobile. While the body of the international literature on the relationship between neighborhood and obesity has expanded in the last decade, contradictory findings 
and the dependence of findings on the particular context invite new studies to strengthen the available evidence.

Municipalities in the southern part of the Dutch province of Limburg have developed a long-term strategy that recognizes that both individual factors and the residential environment (regarding domains such as safety, spatial planning, care, and education) affect the health of residents. ${ }^{29,30}$ Municipal authorities in Southern Limburg (but also in the Netherlands as a whole) have a tradition of monitoring physical and social environments to tailor their policies, and therefore have large amounts of routinely collected data available. This makes this region a suitable area to identify neighborhood effects on overweight and obesity.

The objective of this study was to explore whether overweight and obesity are associated with the specific characteristics of the physical and social neighborhood environment, after accounting for individual demographic factors and socioeconomic status, and whether the association depends on age, gender, and socioeconomic categories. We hypothesize that better scores on the neighborhood environment measures are associated with lower rates of excessive weight, acting via increased physical activity as well as reducing the stress levels also shown to be associated with obesity. ${ }^{13,31,32}$ Further, we expect that these effects are more visible in female and older residents who generally spend more time in the neighborhood, and in lower SES residents who may have fewer resources to compensate for an unfavorable living environment. Results of our study could inform the policymakers as to which of the modifiable neighborhood risk factors could be considered in order to, in the long run, reduce the number of obese and overweight persons.

\section{METHODS}

\section{Source of Data}

We used cross-sectional survey data from the local authorities of Maastricht, the largest municipality in Southern Limburg $\left(122,488\right.$ inhabitants, $\left.60.03 \mathrm{~km}^{233}\right)$. This survey is conducted biannually by the municipal authorities among noninstitutionalized inhabitants and uses a probability sample. A questionnaire is sent to a household, and the person whose birthday comes first after the date on which the questionnaire was received is asked to complete it. The survey includes questions on aspects of the neighborhood environment, such as the quality and accessibility of facilities, safety and nuisance, perceptions of traffic and the built environment, aspects of social capital, health status, demographic and socioeconomic background, and weight and height. The survey is conducted among adults aged 18 years or over. We used the data from the 2010 survey.

Thirty-nine neighborhoods (as defined by "buurt code" by Statistics Netherlands ${ }^{34}$ ) were included in the analyses (150 to 6305 inhabitants per neighborhood). Very small neighborhoods with less than 100 residents (3 neighborhoods) were excluded in advance from the sample.

\section{Variables}

Data were collected on demographics (age and gender), socioeconomic status (education and income), physical activity, height and weight, mental health, and smoking status. Socioeconomic status was measured by level of educational achievement and income group. The six education categories mentioned in the questionnaire were classified as low educational level (primary education, lower 
vocational education, pre-vocational secondary education), secondary education (secondary vocational education, senior general secondary education/pre-university education), or high educational level (Bachelor's degree and higher). Income group was defined as low, middle, or high income and was self-reported by the respondents.

\section{Outcome Variable}

Body mass index (BMI) was a variable of interest. BMI was computed from selfreported weight $(\mathrm{kg})$ and height $(\mathrm{cm})$. BMI was classified into normal weight $(18.5 \geq \mathrm{BMI}<25)$, overweight $(25<\mathrm{BMI} \leq 30)$, and obese $(\mathrm{BMI}>30) .{ }^{19,35}$ Persons who were underweight $(\mathrm{BMI}<18.5)$ were excluded from the statistical analyses because of the low numbers $(n=108(1.1 \%))$ as well as the fact that different mechanisms can be assumed to underlie underweight and overweight/obesity.

\section{Statistical Analyses}

First, we created 12 aggregated measures of neighborhood environment from 52 original survey questions. Factor analysis was used to define aggregated neighborhood characteristics of physical or social environment, which were then used in the current analyses. Scale reliability analyses were performed for identified factors to determine the internal consistency between the indicators grouped in each factor (Cronbach's alpha $>0.7$ ). Next, each factor was labeled based on face validity upon a consensus among the project group members. A total score was computed for each factor. To adjust for different numbers of answering alternatives, each individual component was recoded to a scale of 0 to 10 , where 10 corresponded to the most favorable answer (e.g., for the question with 5 answer categories, the following scores would be assigned: "absolutely not satisfied"=0, "not satisfied" $=2.5$, "not dissatisfied/not satisfied" $=5$, "satisfied" $=7.5$, "very satisfied" $=10$ ). The total score for a factor was computed as the mean of the individual components, which also took values from 0 to 10 . If one individual item score was missing, the mean of the remaining components was taken. If more than one individual component was missing, the total score of the factor was considered to be missing. In total, 12 factors were defined, namely quality and availability of parking facilities, quality and availability of daily shopping facilities, reachability of facilities for daily use, traffic nuisance, quality and availability of green space, social cohesion, general nuisance by people, general feeling of safety, thefts, neighborhood aesthetics (cleanliness), damage to physical environment, and nuisance by drunk people (Table 2). ${ }^{36}$

Next, we fitted multinomial logistic regression models to explore the relationship between each computed measure of physical and social environment and the odds of having normal weight, being overweight, or being obese. Each mean aggregated indicator of a neighborhood environment characteristic was modeled separately as an independent variable, in view of the high correlation between the aggregated indicators and the limited power of the model (total number of neighborhoods $n=39$ ). Each regression model was adjusted for age, gender, and education. As a sensitivity analysis, models were repeated adjusting additionally for income. To explore whether the associations of neighborhood environment characteristics with overweight and obesity depended on demographic or socioeconomic characteristics of the individuals, interactions between individual- and neighborhood-level characteristics (in a fully adjusted model) were tested (cutoff $p$ value for interaction term 
0.05). Analyses were performed on the complete cases available for each model. Statistical significance was assumed at the 0.05 level. Statistical package STATA 12 was used. ${ }^{37}$

\section{RESULTS}

\section{Study Population}

In total, 9771 residents of Maastricht were included in the study (response rate $25 \%$ ). The mean age of the respondents was 55 years, and $50 \%$ were male. Thirtynine percent of respondents were highly educated while $33 \%$ had the lowest level of educational achievement. Most of the respondents $(51 \%)$ classified themselves in the middle income group. In total, half of the respondents met the national norm for physical activity $(54 \%)$, and the average respondent reported engaging in at least moderate physical activity for a minimum of $30 \mathrm{~min}$ a day on 4.1 days per week. Almost half $(44 \%)$ had a normal weight, and 39 and $13 \%$ were overweight and obese, respectively (Table 1 , Online appendix Table 1).

At neighborhood level, substantial differences in socioeconomic characteristics were observed. The percentage of low educated individuals ranged from 9 to $62 \%$, and the percentage of residents who perceived their income as low ranged from 1 to $43 \%$. Substantial differences were found in overweight and obesity rates (33-50 and 3-25\%, respectively). Mean scores on characteristics of neighborhood environment are presented in Table 2.

TABLE 1 Sociodemographic and health-related lifestyle characteristics of the sample

\begin{tabular}{|c|c|c|}
\hline & At individual level & At neighborhood level \\
\hline Variable & $\begin{array}{l}\text { Mean (SD) } \\
\quad[\text { min-max], N (\%) }\end{array}$ & $\begin{array}{l}\text { Min-max of the } \\
\text { neighborhood I } \\
\text { evel indicators }\end{array}$ \\
\hline Age & 55.4 (15.8) [18-98] & $46.3-65.0$ \\
\hline Missing $n$ & $179(1.8)$ & \\
\hline \multicolumn{3}{|l|}{ Gender } \\
\hline Male & $4862(49.8)$ & $41.5-58.1 \%$ \\
\hline Missing $n$ & $171(1.8)$ & \\
\hline \multicolumn{3}{|l|}{ Education } \\
\hline Low & $3255(33.3)$ & $9.0-61.5 \%$ \\
\hline Secondary & $2277(23.3)$ & $4.2-36.8 \%$ \\
\hline High & $3845(39.4)$ & $13.2-71.0 \%$ \\
\hline Missing $n$ & $394(4.0)$ & \\
\hline \multicolumn{3}{|l|}{ Income (self-classified) } \\
\hline Low income & $1952(20.0)$ & $1.0-43.2 \%$ \\
\hline Middle income & $4958(50.7)$ & $24.4-71.3 \%$ \\
\hline High income & $2118(21.7)$ & $4.9-70.4 \%$ \\
\hline Missing $n$ & $743(7.6)$ & \\
\hline \multicolumn{3}{|l|}{ Obesity } \\
\hline Normal weight $(18.5 \leq \mathrm{BMI}<25)$ & $4290(43.9)$ & $33.0-59.5 \%$ \\
\hline Overweight $(25 \leq \mathrm{BMI}<30)$ & $3783(38.7)$ & $32.9-49.5 \%$ \\
\hline Obese $(\mathrm{BMI}>30)$ & $1299(13.3)$ & $3.0-25.3 \%$ \\
\hline Missing $n$ & $399(4.1)$ & \\
\hline
\end{tabular}

\footnotetext{
${ }^{a}$ Range of means among 39 neighborhoods for continuous variables, and range of (lowest and highest) percentage per neighborhood for categorical variables
} 
TABLE 2 Aggregated indicators of social and physical environment

\begin{tabular}{ll}
\hline Neighborhood environment indicator & Neighborhood scores, mean (SD) [min-max] \\
\hline Physical environment & \\
Quality and availability of parking facilities & $5.42(0.71)[3.13-6.94]$ \\
Quality and availability of daily shopping facilities & $7.03(1.44)[0.00-8.59]$ \\
Reachability of facilities for daily use & $6.49(1.04)[1.50-7.78]$ \\
Traffic nuisance & $5.88(0.87)[1.00-7.42]$ \\
Quality and availability of green space & $5.93(0.47)[4.67-7.50]$ \\
Neighborhood aesthetic (cleanliness) & $3.89(0.23)[1.67-5.00]$ \\
Damage to physical environment & $5.33(1.01)[2.50-8.19]$ \\
Social environment & \\
Social cohesion & $6.93(0.59)[5.66-8.02]$ \\
General nuisance by people & $7.67(1.01)[1.25-9.27]$ \\
General feeling of safety & $7.58(0.79)[3.09-8.95]$ \\
Thefts & $6.13(0.95)[4.00-8.52]$ \\
Nuisance by drunk people & $8.42(1.12)[3.79-10.00]$ \\
\hline
\end{tabular}

All aggregated indicators of the neighborhood environment were scored 0 to 10; the higher the score, the more favorable the perception of the situation corresponding to the indicator

\section{Relationship Between Neighborhood Environment Characteristics and Obesity and Physical Activity}

More favorable neighborhood scores regarding quality and availability of daily shopping facilities, reachability of facilities for daily use (such as post office, general practitioner's office and pharmacy, bank and cash dispenser), and neighborhood aesthetics were significantly associated with lower odds of overweight and obesity, regardless of an individual's age, gender, and education (Table 3). Respondents living in neighborhoods with better quality and availability of parking facilities and less nuisance by drunk people were found to be at increased risk of obesity (OR 1.13 and OR 1.08, respectively) and overweight (OR 1.10 and 1.09, respectively). Additionally, quality and availability of green space, social cohesion, general nuisance by people, and general feeling of safety were only significantly associated with obesity as an outcome. In general, stronger associations were found for obesity than for overweight, and for two factors (traffic nuisance and thefts), the associations went in opposite directions for obesity and overweight (Table 3). The range of mean scores for different aspects of the environment varied greatly across neighborhoods, but was never less than two points between the most and least disadvantaged neighborhoods, and reached a difference of as much as 8 points on a 0-10 scale (Table 2). An OR of 0.90 for each point of improvement (on a 0-10 scale) thus yielded a decrease in the risk of excessive weight of $19 \%\left(1-0.90^{2}\right)$ to $43 \%\left(1-0.90^{8}\right)$ in the neighborhoods that scored best on a particular environmental characteristic.

Statistically significant interactions with age were found for nearly all neighborhood characteristics. Stratified analyses across the age groups (young adults (1840 years), middle-aged (41-65 years), and older adults ( $>65$ years) revealed substantially different patterns. In the younger age groups, the associations were in different directions for obesity and overweight, meaning that a more favorable neighborhood environment was both positively and negatively associated with overweight and obesity, depending on the characteristic. At the same time, among the residents of older ages (>65 years), more favorable physical and social 
TABLE 3 Association between the characteristics of the neighborhood and overweight and obesity

\begin{tabular}{|c|c|c|}
\hline $\begin{array}{l}\text { Characteristic of neighborhood } \\
\text { environment }^{a, b}\end{array}$ & $\begin{array}{l}\text { Overweight vs normal } \\
\text { weight }\end{array}$ & $\begin{array}{l}\text { Obese vs normal } \\
\text { weight }\end{array}$ \\
\hline & \multicolumn{2}{|l|}{ Odds ratio $[95 \% \mathrm{Cl}]^{\mathrm{c}}$} \\
\hline \multicolumn{3}{|l|}{ Physical environment } \\
\hline Quality and availability of parking facilities & $1.10[1.04 ; 1.18]$ & $1.13[1.03 ; 1.24]$ \\
\hline $\begin{array}{l}\text { Quality and availability of daily shopping } \\
\text { facilities }\end{array}$ & $0.94[0.91 ; 0.97]$ & $0.94[0.90 ; 0.98]$ \\
\hline Reachability of facilities for daily use & $0.94[0.90 ; 0.98]$ & $0.92[0.87 ; 0.98]$ \\
\hline Traffic nuisance & $1.08[1.02 ; 1.14]$ & $0.91[0.84 ; 0.98]$ \\
\hline Quality and availability of green space & $1.08[0.98 ; 1.20]$ & $0.84[0.73 ; 0.97]$ \\
\hline Neighborhood aesthetics (cleanliness) & $0.81[0.66 ; 0.99]$ & $0.59[0.44 ; 0.79]$ \\
\hline Damage to physical environment & $1.01[0.96 ; 1.05]$ & $0.94[0.88 ; 1.01]$ \\
\hline \multicolumn{3}{|l|}{ Social environment } \\
\hline Social cohesion & $1.00[0.92 ; 1.09]$ & $0.78[0.70 ; 0.88]$ \\
\hline General nuisance by people & $1.05[1.00 ; 1.10]$ & $0.92[0.86 ; 0.98]$ \\
\hline General feeling of safety & $1.06[1.00 ; 1.13]$ & $0.87[0.80 ; 0.95]$ \\
\hline Thefts & $1.07[1.02 ; 1.13]$ & $0.95[0.89 ; 1.02]$ \\
\hline Nuisance by drunk people & $1.09[1.05 ; 1.14]$ & $1.08[1.01 ; 1.15]$ \\
\hline
\end{tabular}

${ }^{\mathrm{a}} n=9034$

${ }^{\mathrm{b}}$ All aggregated indicators of neighborhood environment are scored 0 to 10 ; the higher the score, the more favorable the perception of the situation corresponding to the indicator

'Odds ratios per unit increase of the score, derived from multinomial logistic regression adjusted for individual age, gender, and education category. Estimates with $p$ value $<0.05$ are highlighted in bold

environment characteristics were consistently associated with lower odds of being overweight and obese (Table 4). Reachability of facilities for daily use, traffic nuisance, quality and availability of green space, social cohesion, general nuisance by people, general feeling of safety, and neighborhood aesthetics were among the most prominent characteristics of the neighborhood associated with a lower likelihood of overweight and obesity among the older adults (Table 4).

In females, quality and availability of green space, social cohesion, general nuisance by people, general safety feeling, and thefts were protective factors for obesity, but this did not hold true for males where relationships were either not significant or in the opposite direction (Table 5). No clear patterns in the direction or strength of associations were found between education categories (Online appendix Table 2). Models additionally adjusted for income did not yield different conclusions (results not shown).

\section{DISCUSSION}

The main purpose of the present study was to explore whether obesity and overweight are associated with characteristics of the physical and social neighborhood environment, taking into account individual demographic factors and socioeconomic status, and whether patterns of associations differ for different subgroups in the population.

In the total sample, better quality and availability of daily shopping facilities, reachability of facilities for daily use (such as post office, general practitioner's office 


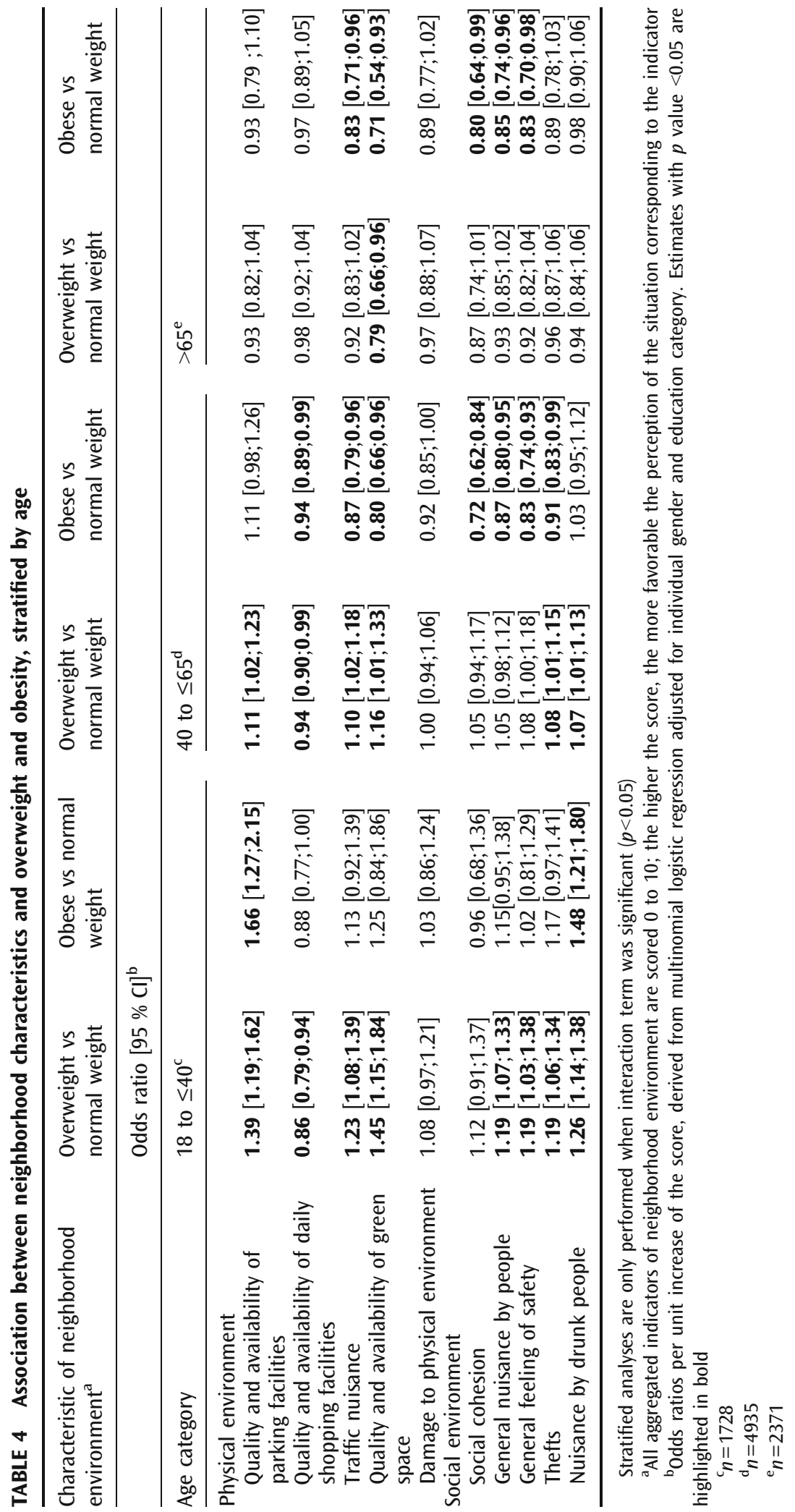




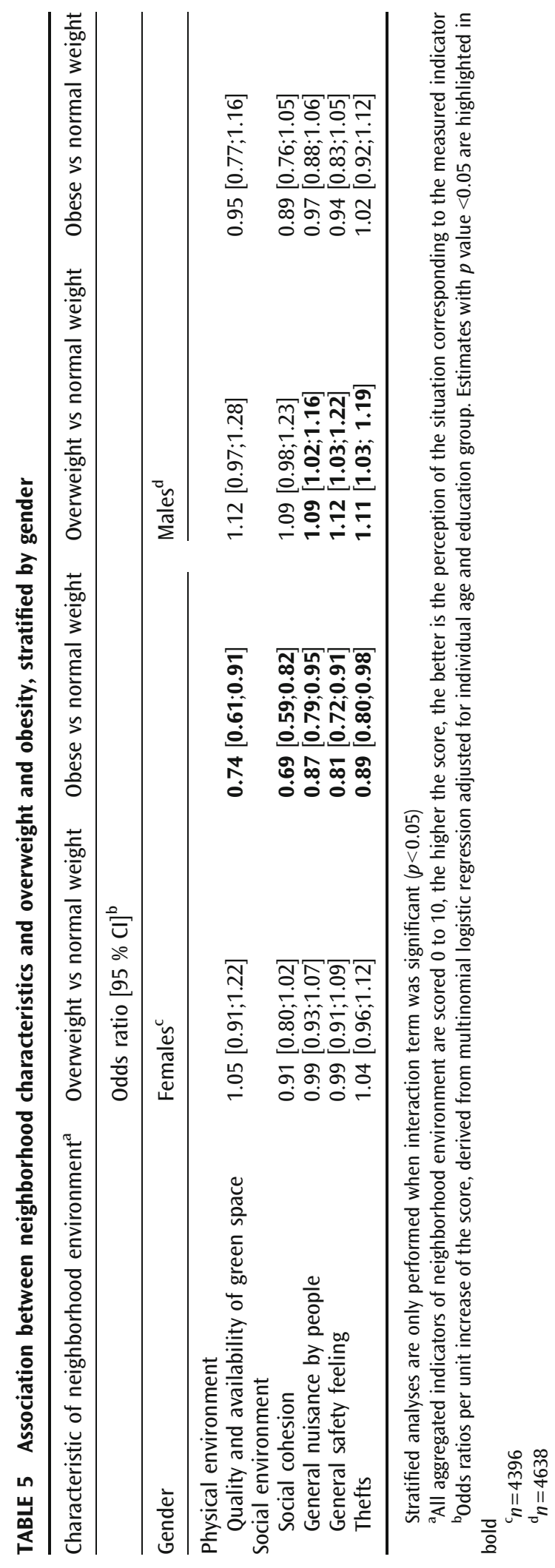


and pharmacy, bank and cash dispenser), and neighborhood aesthetics were associated with lower prevalence of both overweight and obesity (better environment being associated with lower odds of excessive weight). ORs for each point of improvement in the environment on a 0 to 10 scale varied between 0.59 and 0.94 and were statistically significant. Additionally, green space, social cohesion, nuisance, and feelings of safety were only relevant when obesity (BMI $>30)$ was the outcome. As regards traffic nuisance and thefts, associations went in opposite directions: a poorer score on an environment aspect was associated with less overweight but with more obesity, and reverse associations for both overweight and obesity were found for parking facilities and nuisance by drunk people.

Although findings in general sample were generally somewhat inconclusive and the direction of some associations was counterintuitive and hard to explain, analyses stratified by age revealed that in elderly subsamples $(>65)$ an unfavorable physical and social environment was consistently associated with higher levels of obesity among residents. Older residents were more likely to be obese in less cohesive and unsafe neighborhoods, neighborhoods with more traffic nuisance, and those with poor aesthetics. Among all the characteristics we explored, quality and availability of green space had the strongest association with both outcomes in the elderly. Plausibly, older people spend more time outdoors in neighborhoods with more green space, and this has positive impact on BMI via increased physical activity and even reducing stress levels. Green space quality, social cohesion, and safety were also among factors shown to be protective for obesity in females, in addition to nuisance by neighbors. In males, these relationships were either not significant, or even in reverse direction in case of safety and nuisance. Recent study by Bell et al. has observed that associations between neighborhood characteristics and obesity indicators were evident for women only. ${ }^{27}$ It is possible that females spend more time in the neighborhood due to either lower participation in employment or their caregiving responsibilities. ${ }^{27} \mathrm{~A}$ stronger association among older residents might also indicate that duration of exposure to neighborhood characteristics is involved, as elderly, on general, have lived longer in their specific neighborhood.

Stafford and colleagues concluded that in England and Scotland a higher level of neighborhood social disorder and poor access to local high street facilities were factors that might promote higher obesity rates among the residents. These factors were also significant in our analyses (although the wording of the questions in our survey was not identical to theirs). ${ }^{13}$ Social nuisances were also observed to be associated with obesity in an earlier study by Poortinga in England. ${ }^{14}$ Recent studies had contradictory findings in respect of social cohesion, e.g., some authors did not find evidence that social cohesion is related to $\mathrm{BMI}^{15,18}$ while Bjornstrom reported that collective efficacy (trust, cohesion, and the willingness to intervene for the common good among residents) "exerts an independent and beneficial effect on obesity". ${ }^{16}$ In our sample, social cohesion was associated with obesity (but not overweight) and this relationship was more pronounced among older residents.

In agreement with our findings, features of the physical environment were also previously found to be associated with obesity. ${ }^{15,17}$ Recent studies from New Zealand and Europe (including eight countries), which explored several neighborhood factors in relation to outcomes similar to ours in a general adult population mentioned green space (objectively measured) as one of the most relevant characteristics, together with general neighborhood deprivation and aesthetic features. $^{5,38}$ While we have observed similar associations in our Dutch sample, we noticed that green space was not equally relevant across age groups, with results 
being more pronounced for obesity and for middle- and older-aged residents. Powell-Willey et al. observed that perceived traffic nuisance was a risk factor for obesity, while Boehmer et al. reported no such association with an objective traffic safety measure (in a general sample). ${ }^{15,17}$ We could only confirm this association for older residents. Certain discrepancies in findings may be due to the choice of objective and subjective measures. ${ }^{25}$ Moreover, available studies are not directly comparable due to differences in the measurements reflecting the neighborhood environment and the set of confounders used for adjustment. Nevertheless, our results to a large extent confirm the previous and add to the existing knowledge by refined analyses based on age, gender, and education.

Our finding that associations between most neighborhood environment characteristics and obesity are more relevant for older age categories could be explained by the fact that older people are likely to be exposed to the particular neighborhood environment longer and more intensively, while the younger population, on average, would have lived in the neighborhood for a shorter period, and have been less exposed to the neighborhood factors. Effects found in younger subsamples are also more likely to be the result of selection mechanisms, meaning that the choice to live in a specific neighborhood might be influenced by changing individual or neighborhood factors (although selection cannot be completely ruled out for older ages either). It is important that future studies in the field thoroughly explore the age patterns of the neighborhood effects on excessive weight. ${ }^{26}$

A clear strength of our study is the large sample, which allowed us to go into great detail in exploring the effects of neighborhood characteristics in subgroups, something which was previously noted in the literature as lacking. ${ }^{11}$ Another strong point of our study is the practical decision to reduce the number of routinely asked survey questions to a reasonable number of meaningful neighborhood characteristics. ${ }^{36}$ This approach allowed us to make the best use of the rich data set of the survey, while keeping a manageable number of operational concepts in our analyses. Further, we have related outcomes to the perception of neighborhood conditions as reported by co-residents, instead of the respondents themselves, thus overcoming the "single-source" reporting bias. Ours is the first study in the Netherlands and one of few in the international literature to have operationalized neighborhood environment in a large spectrum of specific characteristics (as opposed to exploring only one or a few characteristics of the neighborhood) and explored the relationships with the risk of both overweight and obesity among the residents.

Our study also has a few notable limitations. First of all, the low response to the survey $(25 \%)$ may have biased our findings. While this limitation cannot be disregarded, low response is not necessarily an indicator of poor survey quality. ${ }^{39,40}$ A comparison of the demographics of the sample with data from Statistics Netherlands shows that our sample, although it had a somewhat higher proportion of higher educated individuals, was comparable to the general Dutch population in terms of age and gender. Secondly, a cross-sectional design is commonly mentioned as a limitation, as it precludes conclusions on causal effects. ${ }^{25}$ Currently, all available evidence on this topic comes from cross-sectional studies, and even these are relatively scarce. Although the risk of confounding by unmeasured individual (e.g., ethnicity or cultural factors) or neighborhood-level factors (such as population density or neighborhood-level socioeconomic status) cannot be ignored, we did adjust our models for important individual demographic and socioeconomic variables, namely age, gender, education, and income. Thirdly, while we were able to explore a considerable number of neighborhood factors in relation to obesity and 
overweight, our data did not allow us to assess the independent associations and weigh the relative importance of these factors in a multivariable model. Fourthly, there were some issues related to defining the neighborhood boundaries and the fact that respondents may not refer to the same area in their responses, which have been discussed elsewhere. ${ }^{13,36,41-43}$ A recent Dutch study by Veldhuizen et al. presented an analysis of relationships between socioeconomic variables and health at different area sizes and suggested that administrative areas that are defined on the basis of socioeconomic and geographic criteria (such as neighborhoods in our case) may function well. $^{44}$

Our study adds to a growing body of literature on neighborhood determinants of overweight and obesity in adults. In agreement with existing evidence, we showed that there are neighborhood-level factors that are associated with overweight and obesity, and these could be targeted in preventive strategies outside health care settings. The age of the residents appears to be highly relevant moderator as stronger and more consistent associations between environment and unhealthy weight were observed in older adults. Assuming that future research can confirm the causal character of such associations, the large effect sizes observed demonstrate the great potential of the neighborhood environment for addressing the problem of obesity and overweight. At the same time, individual demographic and socioeconomic characteristics remain important risk factors for obesity, and the population-level strategies could only be considered to complement the individual-level strategies to contain the obesity epidemic.

\section{ACKNOWLEDGMENTS}

We would like to express our gratitude to Maastricht Municipality for sharing the survey data for these analyses.

Funding. No disclosures

Open Access This article is distributed under the terms of the Creative Commons Attribution 4.0 International License (http://creativecommons.org/licenses/by/4.0/), which permits unrestricted use, distribution, and reproduction in any medium, provided you give appropriate credit to the original author(s) and the source, provide a link to the Creative Commons license, and indicate if changes were made.

\section{REFERENCES}

1. WHO, Obesity and overweight. Fact sheet $N^{\circ} 311$. Available at http://www.who.int/ mediacentre/factsheets/fs311/en/. Accessed July 21, 2014.

2. RIVM, Nationaal Kompas Volksgezondheid (www.nationaalkompas.nl). Accessed June 19, 2014.

3. Bouchard C. The biological predisposition to obesity: beyond the thrifty genotype scenario. Int J Obes (Lond). 2007; 31(9): 1337-9.

4. Velasquez-Melendez G, Mendes LL, Padez CM. Built environment and social environment: associations with overweight and obesity in a sample of Brazilian adults. Cad Saude Publica. 2013; 29(10): 1988-96. 
5. Pearson AL, Bentham G, Day P, et al. Associations between neighbourhood environmental characteristics and obesity and related behaviours among adult New Zealanders. BMC Public Health. 2014; 14: 553.

6. Bohdjalian A, Langer FB, Shakeri-Leidenmuhler S, et al. Sleeve gastrectomy as sole and definitive bariatric procedure: 5-year results for weight loss and ghrelin. Obes Surg. 2010; 20(5): 535-40.

7. Dietrich MO, Horvath TL. Limitations in anti-obesity drug development: the critical role of hunger-promoting neurons. Nat Rev Drug Discov. 2012; 11(9): 675-91.

8. Galani C, Schneider H. Prevention and treatment of obesity with lifestyle interventions: review and meta-analysis. Int J Public Health. 2007; 52(6): 348-59.

9. McLaren L. Socioeconomic status and obesity. Epidemiol Rev. 2007; 29: 29-48.

10. Harrington DW, Elliott SJ. Weighing the importance of neighbourhood: a multilevel exploration of the determinants of overweight and obesity. Soc Sci Med. 2009; 68(4): 593-600.

11. Black JL, Macinko J. Neighborhoods and obesity. Nutr Rev. 2008; 66(1): 2-20.

12. Wen M, Kowaleski-Jones L. The built environment and risk of obesity in the United States: racial-ethnic disparities. Health Place. 2012; 18(6): 1314-22.

13. Stafford M, Cummins S, Ellaway A, et al. Pathways to obesity: identifying local, modifiable determinants of physical activity and diet. Soc Sci Med. 2007; 65(9): 1882-97.

14. Poortinga W. Perceptions of the environment, physical activity, and obesity. Soc Sci Med. 2006; 63(11): 2835-46.

15. Powell-Wiley TM, Ayers CR, de Lemos JA, et al. Relationship between perceptions about neighborhood environment and prevalent obesity: data from the Dallas Heart Study. Obesity (Silver Spring). 2013; 21(1): E14-21.

16. Bjornstrom EE. An examination of the relationship between neighborhood income inequality, social resources, and obesity in Los Angeles county. Am J Health Promot. 2011; 26(2): 109-15.

17. Boehmer TK, Hoehner CM, Deshpande AD, et al. Perceived and observed neighborhood indicators of obesity among urban adults. Int J Obes (Lond). 2007; 31(6): 968-77.

18. Christian H, Giles-Corti B, Knuiman M, et al. The influence of the built environment, social environment and health behaviors on body mass index. results from RESIDE. Prev Med. 2011; 53(1-2): 57-60.

19. WHO, Physical status: the use and interpretation of anthropometry. Report of a WHO Expert Committee. WHO Technical Report Series 854, World Health Organization, Editor. Geneva: Switzerland; 1995.

20. Kremers SP, de Bruijn GJ, Visscher TL, et al. Associations between safety from crime, cycling, and obesity in a Dutch elderly population: results from the Longitudinal Aging Study Amsterdam. J Environ Public Health. 2012; 2012: 127857.

21. Kramer D, Maas J, Wingen M, et al. Neighbourhood safety and leisure-time physical activity among Dutch adults: a multilevel perspective. Int J Behav Nutr Phys Act. 2013; 10: 11 .

22. de Vries SI, Hopman-Rock M, Bakker I, et al. Built environmental correlates of walking and cycling in Dutch urban children: results from the SPACE study. Int J Environ Res Public Health. 2010; 7(5): 2309-24.

23. Jongeneel-Grimen B, Busschers W, Droomers M, et al. Change in neighborhood traffic safety: does it matter in terms of physical activity? PLoS One. 2013; 8(5), e62525.

24. Saris C, Kremers S, Van Assema P, et al. What moves them? Active transport among inhabitants of Dutch deprived districts. J Obes. 2013.

25. Ding D, Gebel K. Built environment, physical activity, and obesity: what have we learned from reviewing the literature? Health Place. 2012; 18(1): 100-5.

26. Hrudey EJ, Kunst AE, Stronks K, et al. Do neighborhood characteristics in Amsterdam influence adiposity at preschool age? Int J Environ Res Public Health. 2015; 12(5): 556180 . 
27. Bell JA, Hamer M, Shankar A. Gender-specific associations of objective and perceived neighborhood characteristics with body mass index and waist circumference among older adults in the english longitudinal study of ageing. Am J Public Health. 2014; 104(7): 1279-86.

28. Macintyre S, Elleway A. In: Berkman L, Kawachi I, eds. Ecological approaches: rediscovering the role of the physical and social environment in Social epidemiology. New York: USA; Oxford University Press; 2000: 332-48.

29. Zuid Limburg, Een gezonde koers voor Zuid-Limburg. Regionale nota gezondheidbeleid Zuid-Limburg 2012-2015. 2011.

30. GGD Zuid Limburg, Een gezonde kijk op Zuid-Limburg. Regionale Volksgezondheid Toekomstverkenning 2010: Geleen: The Netherlands; 2010.

31. Seeman TE, Singer BH, Rowe JW, et al. Price of adaptation-allostatic load and its health consequences. MacArthur studies of successful aging. Arch Intern Med. 1997; 157(19): 2259-68.

32. Taylor SE, Repetti RL, Seeman T. Health psychology: what is an unhealthy environment and how does it get under the skin? Annu Rev Psychol. 1997; 48: 411-47.

33. CBS, Kerncijfers wijken en buurten" (Key figures for neighbourhoods). CBS Statline (Statistics Netherlands) (2014). Available from: http://www.cbs.nl/nl-NL/menu/themas/ dossiers/nederlandregionaal/cijfers/incidenteel/maatwerk/wijk-buurtstatistieken/kwbrecent/default.htm. Accessed 28 Sept 2014.

34. CBS, Central Bureau voor de Statistiek (http://statline.cbs.nl/statweb/).

35. WHO, Obesity: preventing and managing the global epidemic. Report of a WHO Consultation. WHO Technical Report Series 894, World Health Organization, Editor: Geneva: Switzerland; 2000

36. Putrik P, de Vries NK, Mujakovic S, et al. Living environment matters: relationships between neighborhood characteristics and health of the residents in a Dutch Municipality. J Commu Health. 2014.

37. StataCorp. Stata statistical software: release 12. College Station: StataCorp LP; 2011.

38. Ellaway A, Macintyre S, Bonnefoy X. Graffiti, greenery, and obesity in adults: secondary analysis of European cross sectional survey. BMJ. 2005; 331(7517): 611-2.

39. Groves RM. Nonresponse rates and nonresponse bias in household surveys. Public Opin Q. 2006; 70(5): 646-75.

40. American association for public opinion research (AAPOR). 2014 July, 2014]; Available from: http://www.aapor.org/Response_Rates_An_Overview1.htm\#.U8LxqrFjPO6. Accessed November 15, 2013

41. Diez Roux AV. Neighborhoods and health: where are we and were do we go from here? Rev Epidemiol Sante Publique. 2007; 55(1): 13-21.

42. Diez Roux AV. Investigating neighborhood and area effects on health. Am J Public Health. 2001; 91(11): 1783-9.

43. Diez Roux AV, Mair C. Neighborhoods and health. Ann N Y Acad Sci. 2010; 1186: 12545.

44. Veldhuizen EM, Stronks K, Kunst AE. Assessing associations between socio-economic environment and self-reported health in Amsterdam using bespoke environments. PLoS One. 2013; 8(7), e68790. 